\title{
Perception \& Psychophysics Articles In Press
}

The following is a list of forthcoming Perception \& Psychophysics articles that are currently in press. They are given in approximate order of acceptance. Each entry includes the name and address of the author with whom to communicate for further prepublication information.

"Naming versus matching in color constancy" by J.M. Troost \& C.M.M. De Weert (J.M.T., NICI, Univ. of Nijmegen, P.O. Box 9104, 6500 HE Nijmegen, The Netherlands)

"Integrating speech information across talkers, gender, and sensory modality: Female faces and male voices in the McGurk effect'" by K.P. Green, P.K. Kuhl, A.N. Meltzoff, \& E.B. Stevens (K.P.G., Cognitive Science, Psychology Bldg., Rm. 312, Univ. of Arizona, Tucson, AZ 85721)

"Bias produced by fast guessing in distribution-based tests of race models" by J. Miller \& A. Lopes (J.M., Dept. of Psychology, C-009, Univ. of California, San Diego, La Jolla, CA 92093-0109)

"Movement and focused attention: A failure to replicate' by A.F. Kramer, M.-P. Tham, \& Y.-Y. Yeh (A.F.K., Dept. of Psychology, Univ. of Ilinois, 603 E. Daniel St., Champaign, IL 61820)

"The effect of ingested alcohol on fusion latency at various viewing distances"' by R.J. Miller (Dept. of Psychology, 209 Johnson Tower, Washington State Univ., Pullman, WA 99164-4820)

"Geometrical illusions in solid objects under ordinary viewing conditions" by P.R. DeLucia \& J. Hochberg (P.R.D., Dept. of Psychology, Texas Tech Univ., Lubbock, TX 794092051)

" On the statistics of subitizing" by J.D. Balakrishnan \& F.G. Ashby (J.D.B., Dept. of Psychology, Northwestern Univ., Evanston, IL 60201)

"Time and duration: A persistent illusion" by G.S. Wasserman (Sensory Coding Lab., Dept. of Psychol. Sciences, Purdue Univ., West Lafayette, IN 47907-1364)

"Duration discrimination of filled and empty auditory intervals: Cognitive and perceptual factors'" by T.H. Rammsayer \& S.D. Lima (S.D.L., Dept. of Psychology, Univ. of Wisconsin, P.O. Box 413, Milwaukee, WI 53201)

"The visual perception of smoothly curved surfaces from minimal apparent motion sequences" by J.T. Todd \& J.F. Norman (J.T.T., Dept. of Psychology, Brandeis Univ., P.O. Box 9110, Waltham, MA 02254-9110)

"Visual search for simple volumetric shapes" by J.M. Brown, N. Weisstein, \& J.G. May (J.M.B., Dept. of Psychology, Univ. of Georgia, Athens, GA 30602)

"Neighborhood frequency effects and letter visibility in visual word recognition'" by J. Grainger, J.K. O'Regan, A.M. Jacobs, \& J. Segui (J.G., Lab. de Psychologie Experimentale, C.N.R.S., 28 rue Serpente, 75006 Paris, France)

"Occlusion as a depth cue in the Wheatstone-Panum limiting case"' by H. Ono, K. Shimono, \& K. Shibuta (H.O., Dept. of Psychology, York Univ., 4700 Keele St., North York, ON, Canada M3J 1P3)
"Spatial-frequency-contingent color aftereffects: Adaptation with one-dimensional stimuli"' by R.H. Day, W.R. Webster, O. Gillies, \& B. Crassini (W.R.W., Dept. of Psychology, Monash Univ., Clayton, Victoria 3168, Australia)

" Spatial-frequency-contingent color aftereffects: Adaptation with two-dimensional stimulus patterns"' by W.R. Webster, R.H. Day, O. Gillies, \& B. Crassini (W.R.W., Dept. of Psychology, Monash Univ., Clayton, Victoria 3168, Australia)

"Perceptual restoration of a 'missing' speech sound: Auditory induction or illusion?' by B.H. Repp (Haskins Laboratories, 270 Crown Street, New Haven, CT 06511-6695)

"Time course of chord priming" by H.G. Tekman \& J.J. Bharucha (H.G.T., Dept. of Psychology, Dartmouth College, Hanover, NH 03755)

"Motion coherence and conjunction search: Implications for guided search theory" by J. Driver, P. McLeod, \& Z. Dienes (J.D., Dept. of Psychology, Univ. of Cambridge, Downing Street, Cambridge CB2 3EB, U.K.)

"Planar motion permits perception of metric structure in stereopsis" by J.S. Lappin \& S.R. Love (J.S.L., Dept. of Psychology, Vanderbilt Univ., Nashville, TN 37240)

"The slippery context effect in psychophysics: Intensive, extensive, and qualitative continua" by L.E. Marks (John B. Pierce Lab., 290 Congress Ave., New Haven, CT 06519)

“Optional processes in similarity judgments" by R.D. Melara, L.E. Marks, \& K.E. Lesko (R.D.M., Dept. of Psychological Sciences, Purdue Univ., West Lafayette, IN 47907)

"Categorical time production: Evidence for discrete timing in motor control"' by C.E. Collyer, H.A. Broadbent, \& R.M. Church (C.E.C., Dept. of Psychology, Univ. of Rhode Island, Kingston, RI 02881)

"Interpolation in structure from motion" by A. Saidpour, M.L. Braunstein, \& D.D. Hoffman (M.L.B., School of Social Sciences, Univ. of California, Irvine, CA 92717)

"Visual parsing and response competition: The effect of grouping factors" by G.C. Baylis \& J. Driver (G.C.B., Dept. of Psychology, 0109, Univ. of California, San Diego, La Jolla, CA 92093)

" Response competition: A major source of interference in a tactile identification task" by P.M. Evans \& J.C. Craig (P.M.E., Dept. of Psychology, Willamette Univ., Salem, OR 97301)

"The spatial and temporal characteristics of perceiving 3-D structure from motion" by D.W. Eby (Dept. of Cognitive Sciences, School of Social Sciences, Univ. of California, Irvine, CA 92717) 